\title{
The Eurozone Crisis-Defining a Path to Recovery
}

\author{
Sean Hagan *
}

Editor's Note: The following essay is drawn from the Diplomat's Forum lecture presented at the University of Kansas School of Law on November 1, 2012, by Mr. Sean Hagan, the General Counsel of the International Monetary Fund (IMF). The Diplomat's Forum is a component of the School's multi-faceted International and Comparative Law Program. Earlier lectures presented in the Diplomat's Forum have featured prominent public servants who have dedicated their careers to diplomacy of various sorts - all working toward an overall goal of improving international relations at all levels. Those individuals have typically served as representatives of their own national governments, including Japan, Austria, the Philippines, and Saudi Arabia, to name a few. The 2012 Diplomat's Forum featured a somewhat different sort of diplomat. The General Counsel of the International Monetary Fund serves in a key diplomatic role, for the IMF itself represents a multilateral effort by nearly all nations in the world to collaborate on an ever-increasing range of international economic issues. In doing so, the IMF - and its Legal Department, of course - continually grapples with some of the world's most difficult problems involving deep cultural, political, and ideological divides, as well as opportunities to bridge those divides. It should be noted that, since this talk was delivered almost five years ago, the Eurozone crisis has abated to a considerable degree. This is due, in large part, to the implementation of the policies that were recommended in these remarks.

In keeping with common practice followed by the KANSAS LAW REVIEW in publishing lectures of this sort, and consistent with the character of the Diplomat's Forum lecture in particular, this article is

\footnotetext{
* Sean Hagan serves as the General Counsel and Head of the Legal Department of the International Monetary Fund. Prior to beginning his work at the IMF, Sean Hagan was in private practice, first in New York and then in Tokyo. He received his Juris Doctor from the Georgetown University Law Center and also received a Master's of Science in International Political Economy from the London School of Economics and Political Science. He has published extensively both on the law of the IMF and on a broad range of legal issues relating to the prevention and resolution of financial crisis, with a particular emphasis on insolvency and the restructuring of debt, including sovereign debt.
} 
structured more in the form of an essay than a traditional law journal article.

$* * * * * *$

\section{INTRODUCTION}

The topic that I have chosen for my remarks is the Eurozone Crisis. I have chosen this topic not only because it is timely but also because it is a global-and not just a regional-issue. How the Eurozone deals with its ongoing problems will not only have enormous impact on the people who live there, but also on the global economy. As you all know, we live in a global village. The complex and interlocking network of trade and capital flows have brought major economic gains and have lifted millions out of poverty. But - and we have seen this from the most recent global financial crisis - our interconnectedness carries important risks as well as benefits. A crisis in one region can have enormous spillover effects in another-including, for example, here in the United States. About a fifth of United States exports go to Europe and, before the crisis, the US S\&P top 500 companies were earning 20 percent of their profits in Europe. Moreover, European-owned companies employ approximately 3.5 million people. So the ability of the United States to restore robust growth and job creation after the most severe crisis since the great depression will be greatly affected by how the Eurozone crisis is resolved.

In my remarks today, I will try to identify what I believe to be the key ingredients to a durable resolution of the problems being encountered by the Eurozone. Not surprisingly, my perspective on these issues is shaped by the fact that I am a staff member of the IMF, which has been actively involved in providing both policy advice and financial and assistance to a number of Eurozone members. At the same time, the views I am expressing here are my own and may not always reflect those of the IMF.

In my view, a sustainable recovery by the Eurozone from this period of instability and uncertainty will require progress in three distinct but interrelated areas: first, effective economic adjustment by its individual members; second, adequate external financing to support this adjustment process; and finally, greater integration among Eurozone members. Let's discuss each of these areas in turn. 


\section{ECONOMIC ADJUSTMENT}

First, there is a need for economic adjustment by individual Eurozone members. When the IMF provides financing to one of our member countries, we are required to ensure that the country in question is taking the steps needed to resolve the underlying problem. We cannot provide financing for the purpose of simply deferring its resolution, even though, from the country's perspective, it may be preferable to do so. This provides the basis for what is generally referred to as IMF "conditionality," where our financing is made contingent upon the country's design and implementation of an economic adjustment program that is designed to enable the country to resolve the underlying cause of its problems.

In the case of those Eurozone members with whom the IMF currently has programs for financial assistance, it is clear that the adjustment process will be a long and difficult one. All of these countries have extremely high debt levels. One of the benefits for a country adopting the euro and entering the Eurozone was that it would thereby be able to access capital markets with considerable ease - indeed they were able to borrow at rates that were only slightly higher than those applicable to Germany. A key objective of the programs we are supporting is the adoption of policies by the country in question that will reduce this debt to a sustainable level. How is this achieved? While fiscal consolidation - that is, a reduction in expenditures and an increase in revenues through taxation-has an important role to play in this process, the IMF is keenly aware that the pace of this adjustment needs to be carefully calibrated, taking into account the circumstances of the country. On the one hand, the establishment of a sufficiently specific and credible policy framework that places public finances on a sustainable path over the medium is critical to restoring market confidence and minimizing uncertainty. We see that not only in Europe, of course, but also in the United States. On the other hand, however, if the pace of fiscal consolidation is too fast, it will not only create excessive social costs but will be economically counterproductive, since it can undermine growth, adversely affecting the level of tax revenues.

Indeed, in the final analysis, a durable resolution of the debt problems of these countries requires the adoption of policies that will generate economic growth. A country's debt level is only sustainable if it can grow out of its debt. This is why economists, and markets as well, assess the sustainability of a country's debt level by measuring it as a percentage of its GDP. 
So the key question for these countries - and for institutions such as the IMF who are providing them with financial support-is how to generate growth. And here, I think there is a consensus that perhaps the most important source of growth is an increase in the competitiveness of the country relative to its trading partners. It is for this reason that the core of all of the IMF-supported programs involves the adoption of policies that are designed to increase competitiveness. Increasing the competitiveness in these countries, however, is a complex task. One of the consequences of the large amount of borrowing that generated current debt levels is that the inflow of money into these economies resulted in a significant increase in prices, which has then undermined competitiveness.

Normally, the solution to this problem is for a country to allow its currency to depreciate relative to other currencies, since such depreciation makes the country's exports cheaper. Of course, this instrument is not available to countries that are members of a currency union, since they do not have their own individual currencies. Rather, in their case, a reduction in prices needs to rely on structural policies, including policies that will increase productivity and lower unit labor costs.

Such structural policies are socially painful - and, for a transitional period, they can also be a drag on growth. For example, while a move toward more competitive wages will eventually make the economy more competitive, in the short term it will reduce demand.

I would note that the issue of whether the prices of southern Eurozone country are sufficiently competitive will also depend on the prices in northern Eurozone countries, their trading partners. Competitiveness is a relative concept. For this reason, efforts to make the economies of the south more competitive through a reduction in prices will be enhanced by corresponding increases in prices in countries of the north-increases which can be achieved through, among other things, the toleration of a higher level of inflation in these countries.

Whatever approach is followed, it is clear that the adjustment path is a narrow, long and steep one. Nevertheless, the governments of those Eurozone members with whom we have programs have decided to pursue this path because they have recognized that the alternative would be even more painful. Unfortunately, public policy is often about choosing between difficult alternatives. While the departure from the Eurozone and the introduction of their own currencies would enable such countries to achieve competitiveness more quickly through a depreciation of those new currencies, it would also result in considerable economic dislocation. 
Why? Because the external debt of the government, banks, corporations, and individuals in each of these countries is all denominated in euros, there would be widespread insolvency due to the fact that, with the inevitable depreciation of the new currency, this debt would have suddenly become much more difficult to service. And finally, for each of these countries, being a member of the Eurozone has served important social and political objectives, and these countries have no doubt judged that a departure would, from that perspective, be too traumatic.

\section{EXTERNAL FINANCING}

Allow me to turn to the second ingredient for success: the availability of adequate external financing that will support the adjustment process. Both the source and the scale of financing will depend on the circumstances of the country in question.

For example, there are those countries - such as Greece, Portugal and Ireland - that have lost access to capital markets because of investors' lack of confidence in the ability of those countries to service their debt. In these cases, the financing needed will come from the official sector, and it will need to be very large. While a country will seek to generate savings to meet its financing needs-including the financing of its large debt-it cannot tighten its belt too fast if it wishes to avoid undermining growth, as I indicated earlier. Accordingly, financial support provided by the official sector can be seen as filling the gap and giving the country more time to implement its adjustment programs - and for these programs to generate the needed results. As these adjustment efforts take hold, the objective is for these members to be in a position to regain access to capital markets. The more financing is available, the more gradual the adjustment process can be. In Europe, the official sector financing provided to these countries has come primarily from the IMF and the EFSF, the European Financial Stability Fund. The recent establishment by the Eurozone of the European Stability Mechanism, which is a permanent institution that succeeds the EFSF, is a very welcome development in this regard.

But just as there are limits to how quickly a member may adjust, so there are also limits to the amount of credit that can be provided by the official sector. The resources of the IMF are finite and, in Europe, we have seen that there are political constraints on how much financing national parliaments are willing to appropriate for this purpose. But perhaps more fundamentally, there may be circumstances in which further credit by the official sector will in fact become 
counterproductive. This situation arises where the debt of the country in question is so high that it is judged to be unsustainable - that is, where under any reasonable adjustment scenario the debt cannot be reduced as a percentage of GDP. Since financing by the IMF and the European institutions creates more debt, our support would exacerbate rather than resolve the problem. In these circumstances, the only available course of action is for the country to obtain relief through a debt restructuring. In effect, the country finds breathing room while it adjusts - but not through new borrowing; rather, that breathing room comes by way of a reduction in the cost of servicing its debt.

This is the strategy that was recently pursued by Greece, where an agreement was reached with private creditors that involved a 75 percent reduction in the net present value of their claims on Greece. Interestingly, although the restructuring did not involve a contractual default, the only reason why creditors agreed to reduce the value of their claims was through a credible threat of default.

At the other end of the spectrum, there are countries such as Spain, which, although it is going through a painful adjustment process, has not lost its access to capital markets. Because of uncertainties, however, markets have increased interest rates that they charge for these countries - a dynamic which, if left unchecked, could result in a complete loss of market access. In these circumstances, financing by the official sector can play what is referred to as a catalytic role. In essence, a commitment of resources by the official sector in support of strong adjustment policies that the official sector endorses can catalyze a restoration of market confidence and, accordingly, lower market costs. In fact, the mere availability of these resources, even if they are not drawn by the member, may have a salutary effect. This is often referred to as precautionary or backstop financing. The recent announcement by the European Central Bank of its Outright Market Transaction Program represents a major breakthrough in the establishment of a financial backstop for these countries. In essence, the ECB has announced that it is willing to purchase an unlimited amount of the sovereign bonds in the secondary market of those countries that have adjustment programs supported by the ESM and the IMF. Among other things, this will ensure that countries following the right policies can finance themselves at reasonable costs while they undertake the needed policy adjustments.

\section{FURTHER INTEGRATION}

This brings me to the third and final ingredient for success in Europe. No matter how credible the economic adjustment is by individual 
countries and no matter how significant the external financing generated by European institutions and the IMF may be, a durable solution to the Eurozone crisis will require further integration among Eurozone members. Indeed, one could argue that the crisis is a crisis of incomplete integration, with markets questioning the long term viability of the euro project.

There are at least two areas where further integration is needed. Let me explore each of these briefly.

\section{V. . . IN BANKING REGULATION}

The first area in which further integration is needed lies in the area banking regulation. One of the consequences of the creation of the euro was the development of a single financial market. While this has brought a number of benefits, the crisis has demonstrated that the stability of this market can no longer be supported by legal and institutional frameworks that operate - and are backstopped financiallyon a national basis. When times were good, the activity of large crossborder banks clearly overwhelmed the supervisory capacity of the national bank regulators - in both home and host countries. And when banks weaken, the reliance on national approaches to bank recapitalization and resolution can weaken the finances of the government - as was amply demonstrated in the case of Ireland.

For this reason, the IMF has long argued for the creation of a banking union within the Eurozone, one which would be based on three interdependent pillars. The first is the creation of a single euro area bank supervisory agency, which would replace the existing "co-ordinated" national supervisory framework. While there would still be scope for national representation in the new supervisory agency, the existence of a new European institution, with a strong central governance framework, would ensure that supervision is conducted from a euro area (rather than national) perspective.

Second, the creation of a euro area bank resolution authority is needed. Recent experience has demonstrated that national resolution frameworks are not able to resolve large financial groups in a manner that both ensures financial stability and limits moral hazard. A new euro area resolution institution would be in a position to resolve financial groups rapidly and in a manner that ensures an adequate contribution by key stakeholders.

Third, a single euro area deposit insurance and resolution fund should be established. The existing national deposit insurance funds have proven inadequate to support large banks and have placed a strain 
on national treasuries. The creation of a euro area deposit insurance system would address this problem and would go a long way in enhancing confidence in the banking system.

Progress is being made in the creation of the first of these three elements of a banking union. Specifically, at the euro area summit in June 2012, it was agreed that a single supervisory mechanism would be created by the end of 2012. While this is a very welcome step, my own view is that the remaining two pillars - a euro area resolution authority and a deposit insurance fund - also need to be put in place as soon as possible, even though I recognize that they will have fiscal consequences for Eurozone.

VI. . . IN FISCAL POLICY AND PRACTICE

This brings me to the second area where further progress is neededthat of further fiscal integration. One of the lessons of the current crisis is that it is not tenable for seventeen completely independent fiscal policies to sit alongside one monetary policy. The agreement that has been reached among the Eurozone members on the creation of a fiscal compact - which imposes legally binding limits on the deficits of euro members - is therefore welcome. However, imposing limits on borrowing needs to be complemented with further expenditures at the euro area level to support stability.

I know that this is a very sensitive subject. And at one level, the crisis has already generated greater fiscal integration with the establishment of the EFSF and now the ESM, both of which are funded by national authorities. But this represents spending that is ad hoc and provided after the crisis has hit, which makes it more expensive. Moreover, it can give rise to recurring market risk as to the adequacy of resources. What is needed is a more automatic crisis prevention fiscal risk sharing framework that supports individual members going through a downturn in a manner that reduces the likelihood that these downturns will turn into a crisis for the entire area. This assistance could take the form of temporary transfers from the federal budget that would provide a safety net for vulnerable groups. Moreover, since a euro area resolution authority and a deposit insurance fund will require financing, the creation of a banking union will also require further fiscal integration. Various ideas have been proposed as to how these expenditures would be financed, including for example, through the creation of short term securities issued by the Eurozone as a whole. 


\section{CONCLUSION}

Let me offer some overarching observations. The good news is that progress has been made in all of the areas that I have identified as being critical for success. Euro area members are implementing economic adjustment measures that are designed to put their public finance in order and enhance their competitiveness. With respect to external financing, the European Stability Mechanism and the OMT represent important breakthroughs. And with respect to further integration, the intention to establish a supervisory authority represents an important step. The difficulty, however, is that more needs to be done and the market continues to be impatient with the pace of reform. The OTM programs need to be used earlier rather than later. Banking union needs to be complete. Some of the measures that I have mentioned are politically sensitive and will take time to put in place-including in the area of fiscal integration. However, even the establishment of a roadmap for future reform in these areas would enhance market confidence in the short term.

For its part, the IMF continues to stand ready to provide both analytical and financial support. As I indicated at the outset, the entire international community has a stake in the successful resolution of this crisis. And as a universal institution charged with securing international financial stability and enhancing the growth of our 185 member countries, the IMF considers the Eurozone crisis to be a matter of its utmost concern - and has therefore placed its highest priority on helping define a path to recover from it. 